\title{
ADVANCES IN MULTI-PHOTON PROCESSES AND SPECTROSCOPY
}


This page is intentionally left blank 


\section{ADVANCES 매}
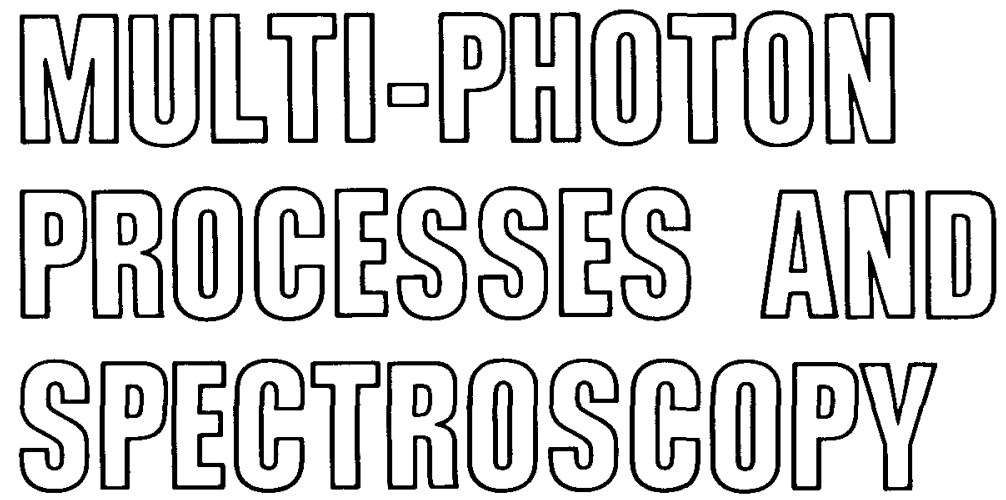

Edited by

$\mathbf{S} \mathbf{H}$ Lin

Department of Chemistry

Arizona State University

Tempe, Arizona 85287. USA 
Published by

World Scientific Publishing Co Pte Ltd.

P O Box 128, Farrer Road, Singapore 9128

\section{ADVANCES IN MULTI-PHOTON PROCESSES AND SPECTROSCOPY}

Copyright (C) 1984 by World Scientific Publishing Co Pte Ltd.

All rights reserved. This book, or parts thereof, may not be reproduced in any form or by any means, electronic or mechanical, including photocopying, recording or any information storage and retrieval system now known or to be invented, without written permission from the Publisher.

ISBN $9971-966-17-4$

Printed in Singapore by Kim Hup Lee Printing Co Pte Ltd. 


\section{P R E F A C E}

In view of the recent rapid growth in both experimental and theoretical studies of multi-photon processes and multi-photon spectroscopy of atoms, ions and molecules in chemistry, physics, biology, materials sciences, etc., it is desirable to publish an Advanced Series that contains review papers readable not only by active researchers in these areas but also by those who are not experts in the field but intend to enter the field. The present series attempts to serve this purpose. In this series, both theory and experiment are equally emphasized, and each review article is written in a selfcontained manner by the experts in the area so that the readers can grasp the knowledge in the area without too much preparation.

The topics covered in this volume are multi-photon processes in atoms (Chapter 1) and in molecules (Chapter 4), multi-photon ionization and multi-photon ionization dissociation of molecules (Chapter 2), Raman spectroscopy applied to structural and conformational problems (Chapter 5) and laser-stimulated rate processes in the gas phase and on solid surfaces (Chapters 3 and 6). The editor wishes to thank the other authors for their important contributions. It is hoped that the collection of topics in this volume will prove to be useful, valuable and stimulating not only to active researchers but also to other scientists in the areas of biology, chemistry, materials sciences, physics, etc. 
This page is intentionally left blank 


\section{CONTENTS}

Preface

Chapter 1. Atomic Multi-Photon Processes

J. H. Eberly and J. Krasinski

Chapter 2. Some Studies on Laser Multiphoton Ionization and Multiphoton Ionization Dissociation of Polyatomic Molecules

D. A. Gobeli, J. J. Yang and M. A. El-Sayed

Chapter 3. Laser-Induced Molecular Dynamics: Rate Processes in the Gas Phase and at Solid Surfaces

J. T. Lin, M. Hutchinson and T. F. George

Chapter 4. Multiphoton Processes by Visible and UV Lasers

I. Tanaka and M. Kawasaki

Chapter 5. Applications of Raman Spectroscopy to Structural and Conformational Problems

J. Laane

Chapter 6. Theory of Laser-Stimulated Surface Processes: Master Equation Approach

B. Fain, A. R. Ziv, G. S. Wu and S. H. Lin 